\title{
An RNA replication-center assay for high content image-based quantifications of human rhinovirus and coxsackievirus infections
}

\author{
Andreas Jurgeit ${ }^{1}$, Stefan Moese ${ }^{3}$, Pascal Roulin ${ }^{1,2}$, Alexander Dorsch ${ }^{1}$, Mark Lötzerich ${ }^{1}$, Wai-Ming Lee ${ }^{4}$,
} Urs F Greber ${ }^{1 *}$

\begin{abstract}
Background: Picornaviruses are common human and animal pathogens, including polio and rhinoviruses of the enterovirus family, and hepatits A or food-and-mouth disease viruses. There are no effective countermeasures against the vast majority of picornaviruses, with the exception of polio and hepatitis A vaccines. Human rhinoviruses (HRV) are the most prevalent picornaviruses comprising more than one hundred serotypes. The existing and also emerging HRVs pose severe health risks for patients with asthma or chronic obstructive pulmonary disease. Here, we developed a serotype-independent infection assay using a commercially available mouse monoclonal antibody (mabJ2) detecting double-strand RNA.
\end{abstract}

Results: Immunocytochemical staining for RNA replication centers using mabJ2 identified cells that were infected with either HRV1A, 2, 14, 16, 37 or coxsackievirus (CV) B3, B4 or A21. MabJ2 labeled-cells were immunocytochemically positive for newly synthesized viral capsid proteins from HRV1A, 14, 16, 37 or CVB3, 4. We optimized the procedure for detection of virus replication in settings for high content screening with automated fluorescence microscopy and single cell analysis. Our data show that the infection signal was dependent on multiplicity, time and temperature of infection, and the mabJ2-positive cell numbers correlated with viral titres determined in single step growth curves. The mabJ2 infection assay was adapted to determine the efficacy of antiviral compounds and small interfering RNAs (siRNAs) blocking enterovirus infections.

Conclusions: We report a broadly applicable, rapid protocol to measure infection of cultured cells with enteroviruses at single cell resolution. This assay can be applied to a wide range of plus-sense RNA viruses, and hence allows comparative studies of viral infection biology without dedicated reagents or procedures. This protocol also allows to directly compare results from small compound or siRNA infection screens for different serotypes without the risk of assay specific artifacts.

\section{Background}

The family of picornaviridae comprises a wide variety of human and animal pathogens [1]. Notable members of the twelve genera are the enteroviruses, such as poliovirus, the causative agent for poliomyelitis, which affected millions of people before broad vaccinations became available in the last decades. Within the picornavirus subgenera, the number of serotypes per species varies from three in the case of poliovirus up to more

\footnotetext{
* Correspondence: urs.greber@imls.uzh.ch

'Institute of Molecular Life Sciences, University of Zurich, Winterthurerstrasse 190, CH-8057 Zurich, Switzerland

Full list of author information is available at the end of the article
}

than one hundred for human rhinoviruses (HRV). HRVs are the main cause of common cold [2], and for recurring infections in humans [3]. HRV infections lead to severe exacerbations in patients with asthma or chronic obstructive pulmonary disease [4]. HRVs comprise species A, B and C [2]. Twelve HRVs from species A bind to the minor receptors from the low density lipoprotein (LDL) receptor family, and the other $61 \mathrm{~A}$-members as well as the B-viruses bind to intercellular adhesion molecule 1 (ICAM-1) for infection [5]. The receptor(s) for the HRV-C serotypes are unknown. The enterotropic coxsackieviruses $(\mathrm{CV})$ can cause myocarditis, pancreatitis and meningitis. The hepatitis A hepatovirus is 
responsible for mild forms of human hepatitis. An example of a non-human picornavirus is the foot-andmouth disease virus of the apthovirus genus, which induces lesions in cloven-hoof animals, such as cattle, swine, goat, sheep and buffalo, and is the cause for tremendous economic losses, as experienced during the last outbreak in England in 2001 [6].

Picornaviruses are small, non-enveloped RNA viruses with an icosahedral capsid of about $28-30 \mathrm{~nm}$ in diameter [7], and a single strand, plus-sense RNA genome, which is in case of enteroviruses about 7.2 to $8.45 \mathrm{~kb}$ [8]. The genome encodes a single polyprotein that is proteolytically processed by viral proteases into structural and non-structural proteins. The replication of picornaviruses takes place in the cytoplasm in close association with endo-membranes containing single-and multi-membrane vesicles and complex membranous structures of various sizes [9]. Cytoplasmic membranes are well known to support the replication of plus-sense RNA viruses, for example the alphavirus Semliki Forest virus [10-12], the rubivirus rubella virus $[13,14]$, the enterovirus poliovirus [15], or the flaviviruses hepatitis $C$, Dengue and West Nile viruses [16-18], where it is referred to as membranous web. Membrane associated replication structures are thought to protect the replicating viral RNA from anti-viral factors recognizing double-strand RNA (dsRNA), and may provide a scaffold for anchoring and locally concentrating the viral replication complexes. Since its establishment requires de novo lipid synthesis, it may represent an anti-viral target, as suggested from work with drosophila $C$ virus, a dicistronic virus, which is in many ways similar to picornaviruses, for example, encoding a polyprotein by a single positive-strand RNA genome, or using capindependent, internal ribosome entry site-dependent translation $[19,20]$.

The replication process of viruses has been a target for classical anti-viral agents directed against proteases, polymerases or integrases in the case of human immunodeficiency syndrome viruses (HIV) or hepatitis C viruses (HCV) [reviewed in [21]]. Enterovirus inhibitors have been developed against the HRV protease 3C [22] or the capsid uncoating mechanism [for example, pleconaril, [23]]. Alternative approaches against host factors that support viral replication included protein kinases involved in virus entry, such as the serine/threonine kinase PAK1 for echoviruses, adenoviruses or vaccinia virus [24-28], as well as tyrosine kinases for coxsackievirus B3-RD [29] or microbial pathogens [for a review, see [30]]. To enhance the identification of anti-viral agents, standardized infection assays should be developed for cultured cells as a basis for high throughput screening projects.
Here we describe a simple immunofluorescence-based infection protocol to quantitatively assess infection of cultured cells with enteroviruses, using the mouse monoclonal anti-dsRNA antibody J2 [mabJ2, [31]]. It recognizes dsRNA duplexes larger than about $40 \mathrm{bp}$ and was used earlier to detect replicating HCV genomes in distinct cytoplasmic foci [32], or RNA replication intermediates from the groundnut rosette virus RNA-dependent RNA polymerase [31]. The cytoplasmic foci recognized by mabJ2 are similar to foci recognized by an anti-dsRNA serum in rubella virus or Semliki Forest virus-infected cells $[13,33]$. We found that the appearance of mabJ2-positive dsRNA replication centers in HRV or coxsackievirus infected cells correlated with the emergence of capsid protein epitopes and infectious virus titer, and the mabJ 2 assay was applicable for prototypic high throughput, image-based siRNA and small compound screens.

\section{Results}

Double-strand RNA replication centers identify HRV and coxsackievirus infected cells

We first tested if the formation of dsRNA-positive replication centers can be used as an assay for infection of HeLa cells strain Ohio (herein referred to as HeLa) with HRV or CV. HeLa cells are widely used to isolate and study HRVs and other enteroviruses [34]. Cells were infected at low multiplicity of infection (moi 0.2-0.4) with HRV1A, 14, 16, 37 or CVB3 or B4, and co-stained by double label immunofluorescence for dsRNA using mabJ2, and newly synthesized viral proteins using mabR16-7-Alexa488 (conjugated with Alexa488 dye) or a rabbit polyclonal antibody raised against purified capsid proteins (Fig. 1A). MabR16-7 had been raised against HRV16 and recognized VP2 from both HRV16 and 1A [35]. As expected, all cells positive for newly synthesized viral protein were also positive for dsRNA detected by mabJ2, and replication foci had a subcellular localization similar to cytoplasmic foci, which had been reported earlier as replication centers in picornavirus-infected cells $[15,36]$. Performing a similar experiment with the mabK1, detecting dsRNA >40bp, gave identical results, although with lower signal intensity (data not shown). We hence used mabJ2 for all following experiments.

Attempts to detect incoming viral particles by mabJ2 failed, although incoming HRV16 have been successfully visualized with mabR16-7, detecting a capsid epitope (data not shown). This was in agreement with the notion that mabJ2 detects long duplexes of doublestrand structures of the replicating RNA rather than genomic RNA, that is, most likely duplexes of postive and negative-strand RNAs [31,32]. Biochemical assays estimated the numbers of negative-strand RNA copies 
A dsRNA replication centers and newly synthesized viral protein
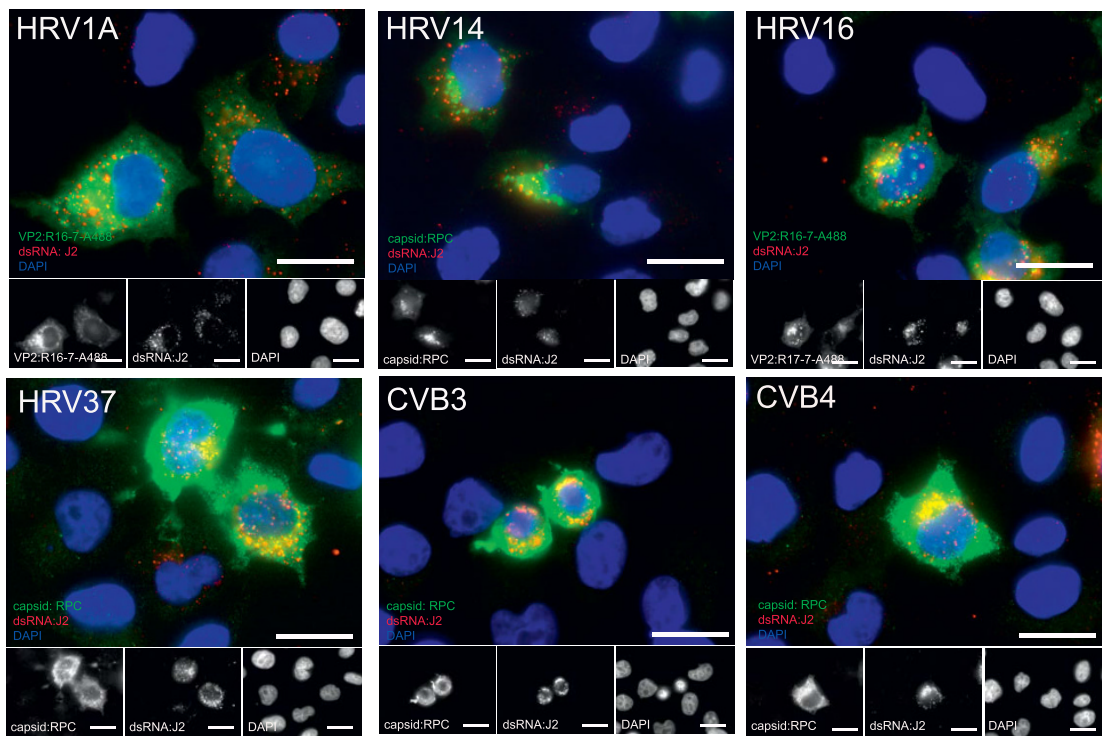

B moi dependent dsRNA replication centers

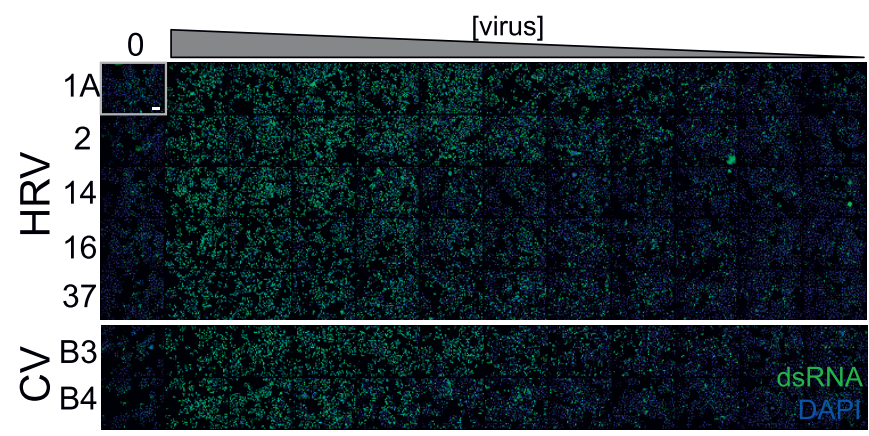

C automated image analysis for high content screening D moi dependent infection scoring
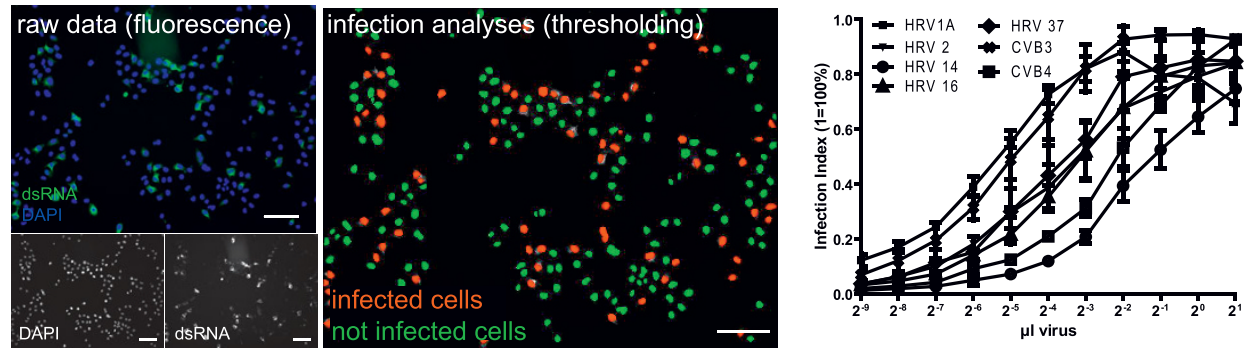

Figure 1 MabJ2 detects viral replication-induced dsRNA in high content image based assays. (A) Cells with dsRNA replication centers are positive for newly synthesized viral protein. HeLa cells were infected with the indicated HRV or CV serotypes, fixed and stained with mabJ2 (red) or capsid specific antibodies (green). CVB3, CVB4, HRV37 and HRV14 were stained with a rabbit polyclonal serum (rpc); HRV1A and 16 were stained by mabR16-7 covalently labelled with Alexa488 (R16-7-488). Magnification 60x; scale bar $20 \mu \mathrm{m}$. (B) Appearance of dsRNA replication centers is moi dependent. Example overview of a 96 multiwell plate of HeLa cells infected with serial dilutions of indicated HRV or CV serotypes. Imaging by automated microscopy was with 10x magnification. One out of nine images per well is shown for each condition. dsRNA replication centers (green) and DAPI stained nuclei (blue) are shown. Scale bar $100 \mu \mathrm{m}$. (C) An example for automated fluorescence image analysis to score infection of HeLa cells with HRV16 (moi 0.3) with raw images on the left and an image processed and pseudocolored with a Matlab algorithm on the right side. Scale bar $100 \mu \mathrm{m}$. (D) Example for the quantification of moi dependent fraction of infected cells (infection index) of the experiment shown in (B), and analysis by the scoring algorithm presented in (C). More detailed characterisations (time, dose) of this assay are shown in the subsequent figures. 
in poliovirus infected HeLa cells to about 1000 per cell at the log phase of replication, corresponding to a few percent of the total viral RNA [37]. Since poliovirus replicates to higher levels than HRV in HeLa cells as determined, for example, in single step growth curves (WML, unpublished), we suggest that our image-based assay detects less than 1000 dsRNA molecules per cell. Although it might be possible to correlate the mabJ2 signal intensity with the viral RNA load per cell, this would require higher resolution image acquisition and quantitative measurements, and hence would reduce the throughput of the assay, and require orders of magnitude more data to be processed, which would limit the utility of this assay for screening purposes.

To test if the mabJ2 assay is useful for high-content, image-based infection screens, we infected HeLa cells with serial dilutions of different HRV and CV serotypes in multiwell plates, followed by staining with mabJ2 and counterstaining of the cell nuclei with 4',6'-diamidin-2phenylindol (DAPI, Fig. 1B). Non-infected cells did not show detectable signals from mabJ2, while cells inoculated with HRV1A, 2, 14, 16, 37 or CVB3 or B4 showed dose-dependent mabJ2 signals. Infected cells were quantified using a custom-written Matlab routine. This algorithm scored cells as infected, if the DAPI signal overlapped with a thresholded infection marker, which were either the newly synthesized viral protein or dsRNA replication centers (Fig. 1C, and additional file 1, Fig. S1). This analysis did not discriminate between "weak" and "intense" infection signals, but rather scored cells as infected if certain criteria were met (see details described in the methods section and additional file 1 , Fig. S1). The analysis confirmed that the mabJ2 infection assay was robust and specific for HRV1A, 2, 14, 16 and CVB3, B4 infections in a dose-dependent manner (Fig. 1D).

For a biological validation of the mabJ2 assay, we performed a receptor interference experiment using the mouse monoclonal antibody mab15.2L to block the binding site of major HRV serotypes 14, 16 and 37 and CVA21 on the intracellular adhesion molecule 1 (ICAM-1) [38-40]. As expected, for ICAM-1 tropic HRVs and CVA21, receptor blocking led to a $>90 \%$ decrease of infection, whereas minor group HRVs and CVB3, which use the low density lipoprotein (LDL)receptor or coxsackievirus adenovirus receptor (CAR), respectively [41,42], were not affected (Fig. 2). Note that a low amount of mabJ2 signal (approximately 5\%) was detected in non-infected cells treated with the mouse anti-ICAM-1 antibody, but not in non-antibody treated cells, and hence represents the reactivity of the secondary anti-mouse antibody (see additional file 2, Fig. S2). We conclude that the mabJ2 replication center assay is reliable and has a good signal-to-noise ratio.

\section{Towards high content image based infection screening}

To determine optimal conditions for high content infection assays we performed time course and titration experiments with HRV1A, 2, 14, 16 and 37 and CVB3 and B4. As expected from the initial experiments (see Fig. 1B, D), the dsRNA infection assay scored a timeand dose-dependent increase of the infection index for HRV16 and CVB3 (Fig. 3A, B), and also for the other viruses (additional file 2, Fig. S2). We found that an infection at low moi (less than 0.5 ) for $7 \mathrm{~h}$ at $37^{\circ} \mathrm{C}$ was optimal for HRVs and CVs. Longer infection times led to cytopathic effects and loss of infected cells from the culture dish. Notably, HRV infections were similar or even more efficient at $37^{\circ} \mathrm{C}$ compared to at $33.5^{\circ} \mathrm{C}$, whereas CVB3 and B4 infections were attenuated at $33.5^{\circ} \mathrm{C}$ (Fig. 3A, B, and additional file 3, Fig. S3). The strong attenuation of $\mathrm{CVs}$ at $33.5^{\circ} \mathrm{C}$ was expected. The good growth characteristics of $\mathrm{HRVs}$ at $37^{\circ} \mathrm{C}$ was consistent with recent data showing that HRVs replicate well at core body temperature $[43,44]$ and are associated with lower respiratory tract infections $[3,35,45,46]$. In addition, the dsRNA mabJ2 assay detected increasing infection rates in time course experiments with all the five HRVs and both coxsackieviruses (additional file 4, Fig. S4), further confirming the specificity of the assay.

We next asked if the mabJ2 replication signal from HRV1A and 16 correlated with viral titers produced in the infected cells. We found a strong correlation between the number of infected cells detected by mabJ2 in the producer cells (dubbed 'infection') and infectious virus production by the infected cells, as determined by single step growth curves yielding more than 30-fold higher titers than inoculum (Fig. 3C). This is in close agreements with reports from the literature [47]. We conclude that mabJ2-positive cells produce infectious particles confirming that the image based dsRNA infection assay can also be used for high throughput full cycle infection assessments.

\section{The RNA replication assay for studies with antiviral compounds}

We next tested the performance of the mabJ2 dsRNA detection assay with the HRV and CV entry inhibitor pleconaril [23]. Pleconaril binds in the hydrophobic pocket of the capsid protein VP1 of several enteroviruses [48], and thereby prevents conformational changes in the capsid that enable RNA release upon receptor-mediated endocytosis. The concentration for $50 \%$ inhibition (IC50) of pleconaril in our dsRNA-based infection assay ranged from $0.01 \mu \mathrm{g} / \mathrm{ml}$ for the highly sensitive CVB4 up to $0.05 \mu \mathrm{g} / \mathrm{ml}$ to $0.1 \mu \mathrm{g} / \mathrm{ml}$ for the majority of HRVs (Fig. 4A, color code as in panel B). Our CVB3 strain was resistant to pleconaril in accordance with data from the literature [48]. 


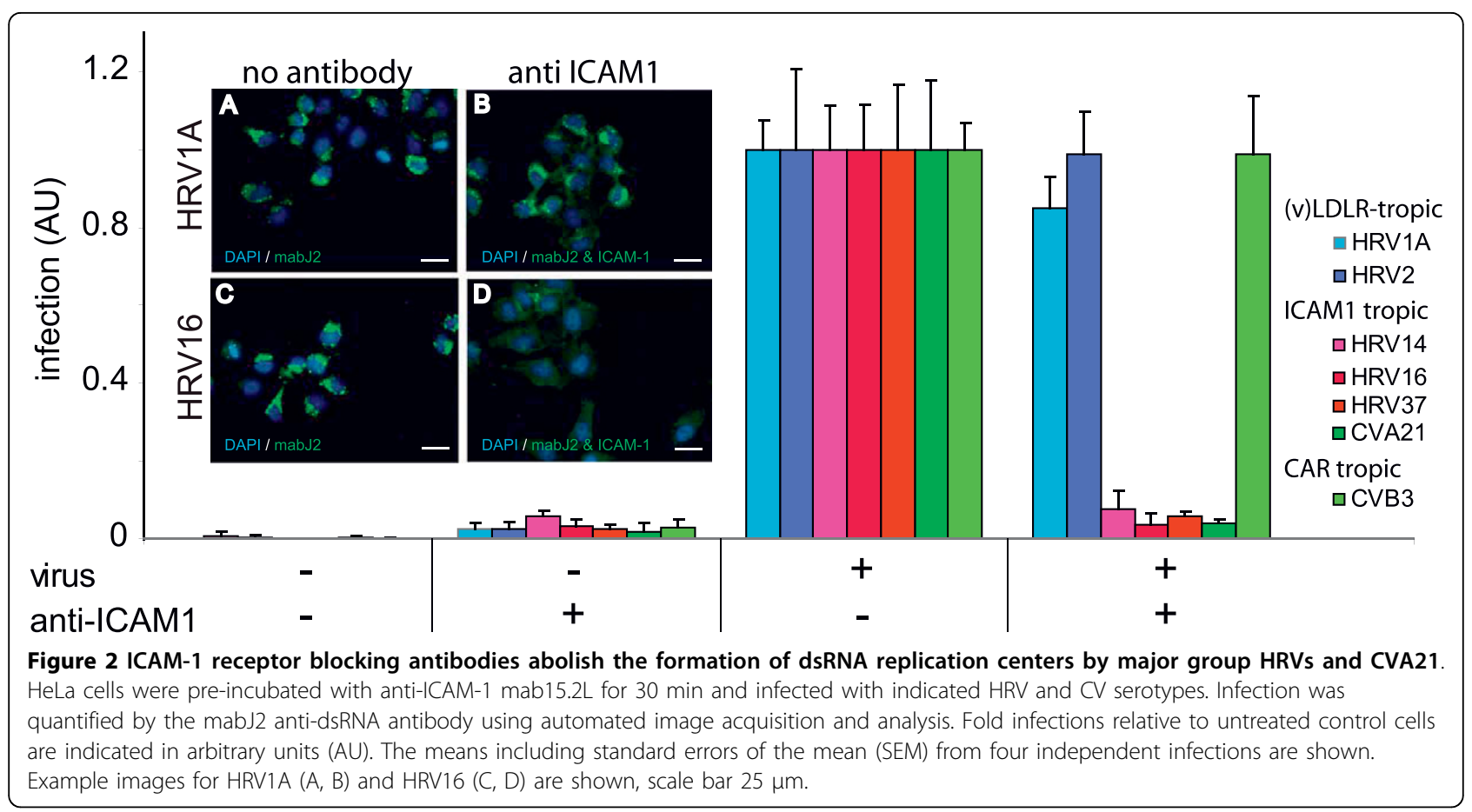

To test if the dsRNA infection assay can be used to determine at which step of the viral life cycle a particular compound blocks infection, we performed successive compound addition experiments. Cells were treated with pleconaril either prior to infection or at defined time points post infection (pi). Pleconaril strongly inhibited infection only when added at early time points (up to about $45 \mathrm{~min}$ ) post infection (pi) (Fig. 4B), in agreement with the notion that it inhibits the entry and conversion steps of the capsid prior to release of the RNA genome, but not genome replication [49].

To address if the dsRNA replication assay responded to downstream replication blocking agents, we treated cells with guanidine- $\mathrm{HCl}$, which blocks the enteroviral protein $2 \mathrm{C}$ and specifically prevents the initiation of negative-strand RNA synthesis but not translation of the polyprotein [50-53]. All five HRVs (1A, 2, 14, 16, 37) and CVB3 and B4 were sensitive to the highest concentration of guanidine- $\mathrm{HCl}$ tested $(20 \mathrm{mM})$, but HRV1A and HRV16 were not inhibited by intermediate concentrations of $2 \mathrm{mM}$ (Fig. 4C), which could be related to the close genetic relationship of HRV1A and 16 [5]. The lowest concentration of guanidine $(0.2 \mathrm{mM})$ inhibited HRV14 and 37, but none of the other viruses, which may also reflect the genetic diversity of the $2 \mathrm{C}$ protein [see for example, [5]]. Consistent with guanidine inhibition of replication but not upstream processes of infection, we found that $2 \mathrm{mM}$ guanidine blocked the appearance of dsRNA mabJ2 epitopes when added up to $120 \mathrm{~min}$ pi for CVB3, and up to $240 \mathrm{~min} \mathrm{pi}$ for the slower replicating and highly guanidine-sensitive HRV14 (Fig. 4D). The guanidine insensitive HRV1A and 16 remained rather unaffected by guanidine in the time course experiment confirming the results from the dose-dependent pre-incubation experiment (Fig. 4C). Together, these data illustrate that the dsRNA imagebased replication assay is applicable for screening of small anti-viral compounds and determining the time point of their maximal efficacy in the viral replication cycle.

\section{Application of the RNA replication assay for image-based siRNA screens}

siRNA profiling in cultured cells has been widely used to identify host factors with potential therapeutic impact for anti-viral or anti-microbial interference, but there were only a few genes commonly identified in the different screens. To reduce some of the technical variables for siRNA screenings in viral infections, we evaluated the mabJ2 infection assay for its applicability in high content image-based siRNA infection screens with a prototype library of 137 host factors, and a set of defined controls targeting the HRV genome, that is, three siRNA oligos per target, a total of 490 individual data points including scrambled siRNAs and-non-treated controls. Infection of HeLa cells with HRV14 was scored by mabJ2 staining and a rabbit polyclonal antibody against structural proteins of HRV14 (W.M. Lee, unpublished). Inspection of the primary imaging data revealed a strong correlation of the extent of infection determined by staining for newly 

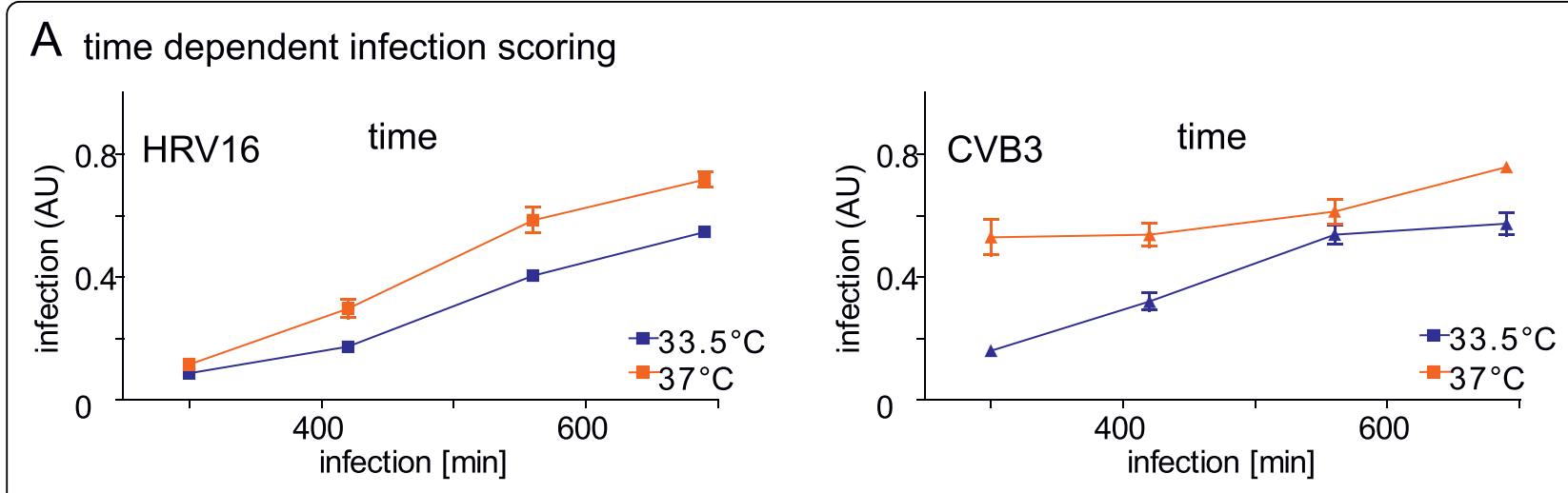

\section{B dose dependent infection scoring}
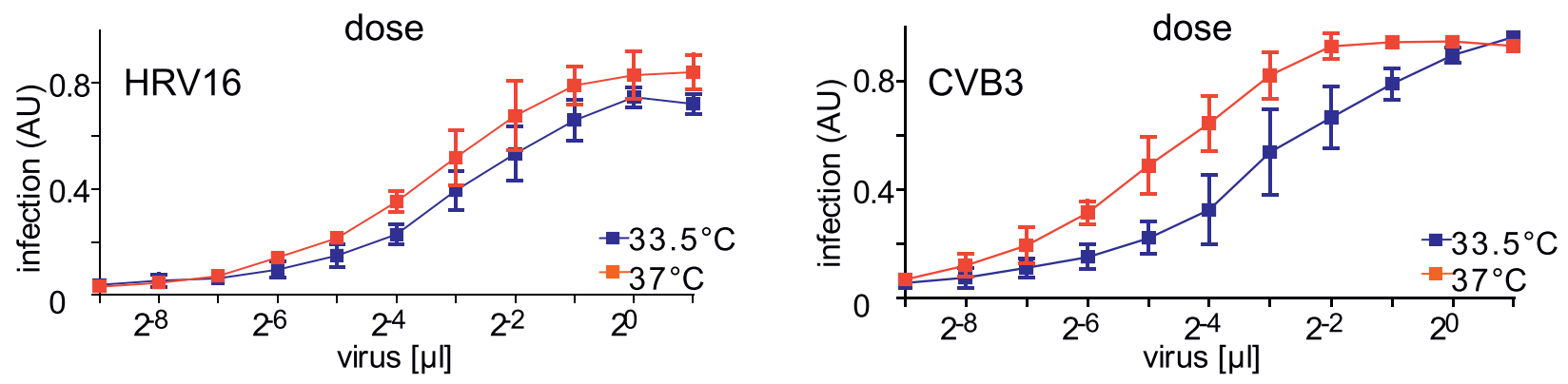

\section{C single cycle growth curve}
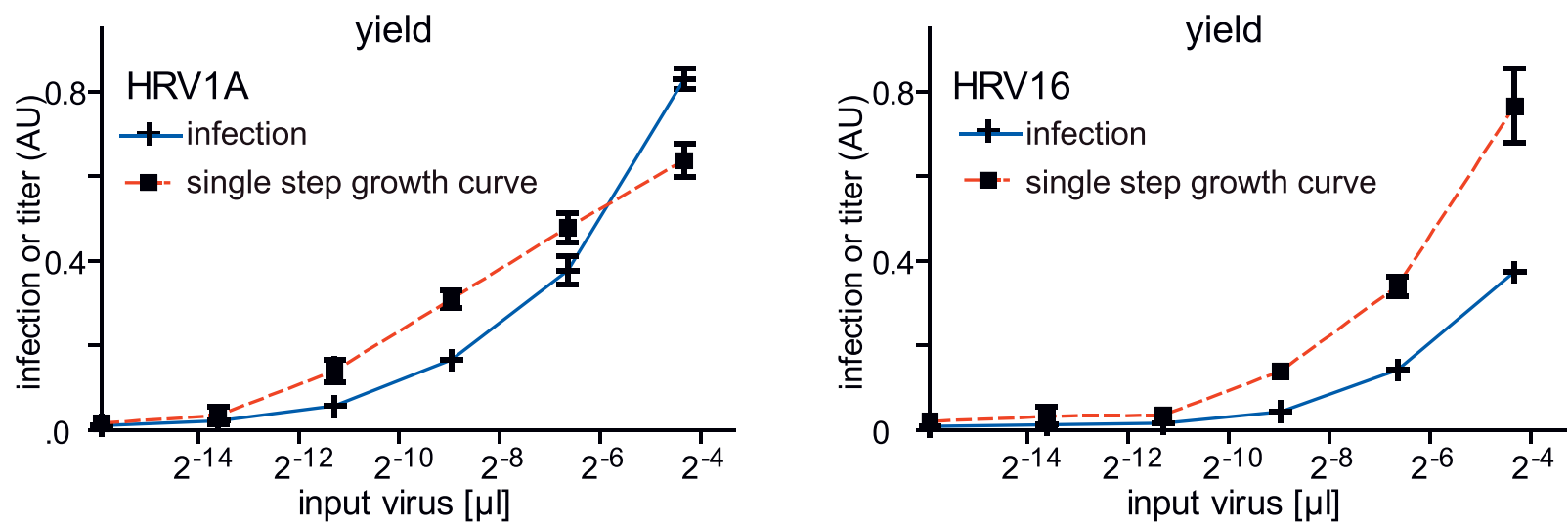

Figure 3 Appearance of dsRNA replication centers is time, dose and temperature dependent and correlates with emergence of infectious titres. (A, B) The time and dose dependencies of HRV16 and CVB3 infections at $33.5^{\circ} \mathrm{C}$ (blue) or $37^{\circ} \mathrm{C}$ (red) were determined using the mabJ2 dsRNA infection assay in HeLa cells by either infection for 300 to $700 \mathrm{~min}$, or with two fold serial dilutions of inocula. (C) To determine the correlation of mabJ2 dsRNA staining with viral titre production, HeLa cells were infected with HRV1A or 16 for $16 \mathrm{~h}$ (infection, blue) with serial dilutions of inocula. Newly synthesized particles were released from in parallel treated cells by three freeze/thaw cycles and inoculated on naïve HeLa cells to obtain single step growth curves (red). Infection was scored using automated image analysis. Means and SEMs of one representative triplicate are shown.

synthesized viral protein or the dsRNA replication centers (Fig. 5A, B). Likewise, comparing the log2 infection indices between three independent siRNA screens of HRV16-infected HeLa cells showed strong correlations $(\mathrm{R} 2>0.9)$ among the three independent replica screens using both a viral capsid specific antibody (mabR16-7) and the dsRNA infection assay (Fig. 5C). These data demonstrate that mabJ2 can be employed for detection of RNA replication centers in high throughput imagebased infection screens. 


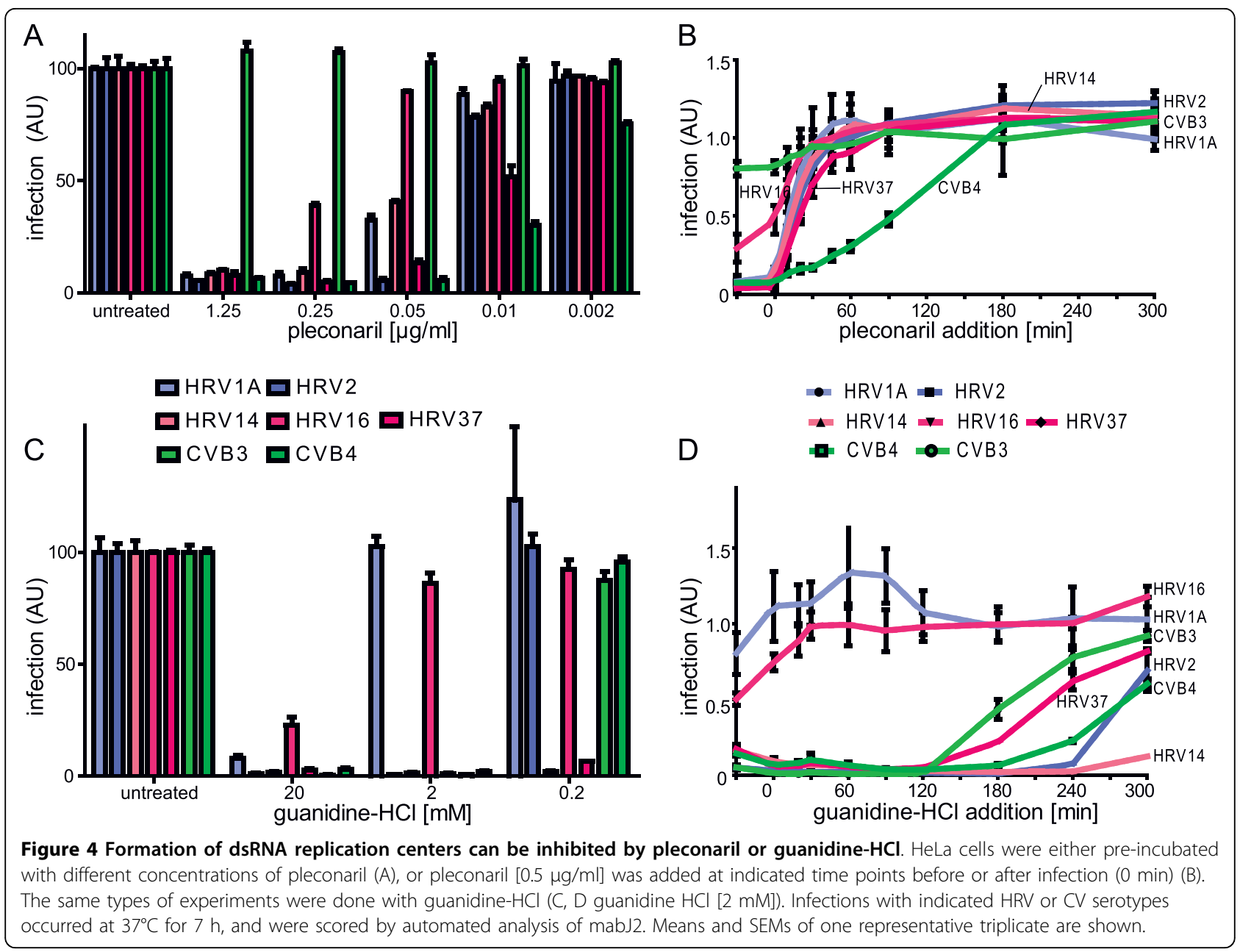

The RNA replication center assay detects infection of non-transformed human WI-38 fibroblasts

Finally, we also tested if mabJ2 recognized HRV-infected WI-38 primary human lung fibroblasts. We readily detected mabJ2-positive cells inoculated with the two minor group serotypes HRV1A and HRV2 (Fig. 6A). HRV1A and HRV2 infections were dependent on the temperature and inoculum dose, as indicated by analyses at 7 and $8 \mathrm{~h}$ pi (Fig. 6B, C). In addition, both infections were strongly attenuated by an inhibitor of the vacuolar ATPase, bafilomycin A1, in a dose-dependent manner with an IC50 of $1 \mathrm{nM}$ [Fig. 6D, E, [54]]. These data were in agreement with earlier reports showing that infectious cell entry of minor group HRVs, as shown with HRV2, was dependent on low endosomal pH [55], and that both HRV1A and HRV2 were readily inactivated by low $\mathrm{pH}$ solutions in vitro [data not shown, and [56]]. To our surprise, however, the major group viruses HRV14 as well as CVB3 and B4 did not lead to detectable formation of mabJ2-positive replication centers in WI-38 cells up to $8 \mathrm{~h} \mathrm{pi,} \mathrm{even} \mathrm{at} \mathrm{high} \mathrm{moi} \mathrm{(100-1000}$ times higher than for HeLa cells), while HRV16, HRV37 and CVA21 gave low levels of mabJ2 signals (Suppl. Fig. 5). These data show that mabJ2 detects subtle differences in infection levels in cultured cells.

\section{Discussion}

Comprehensive studies of the vast number of enterovirus serotypes and their cell biological mechanisms of infection are a key foundation for developing new antiviral therapies. Progress in this area has been limited by the lack of reagents to detect infection of all the serotypes, and hence it has remained difficult to stringently compare the infection mechanisms from different virus serotypes or families.

Here we present a dsRNA replication center assay that can be used to detect infections by a broad range of enteroviruses in HeLa cells, that is, five human rhinovirus and three coxsackievirus serotypes. In the case of the minor HRV serotypes HRV1A and HRV2 the assay also detected infection of primary human lung WI-38 fibroblasts. The assay is applicable for high content 


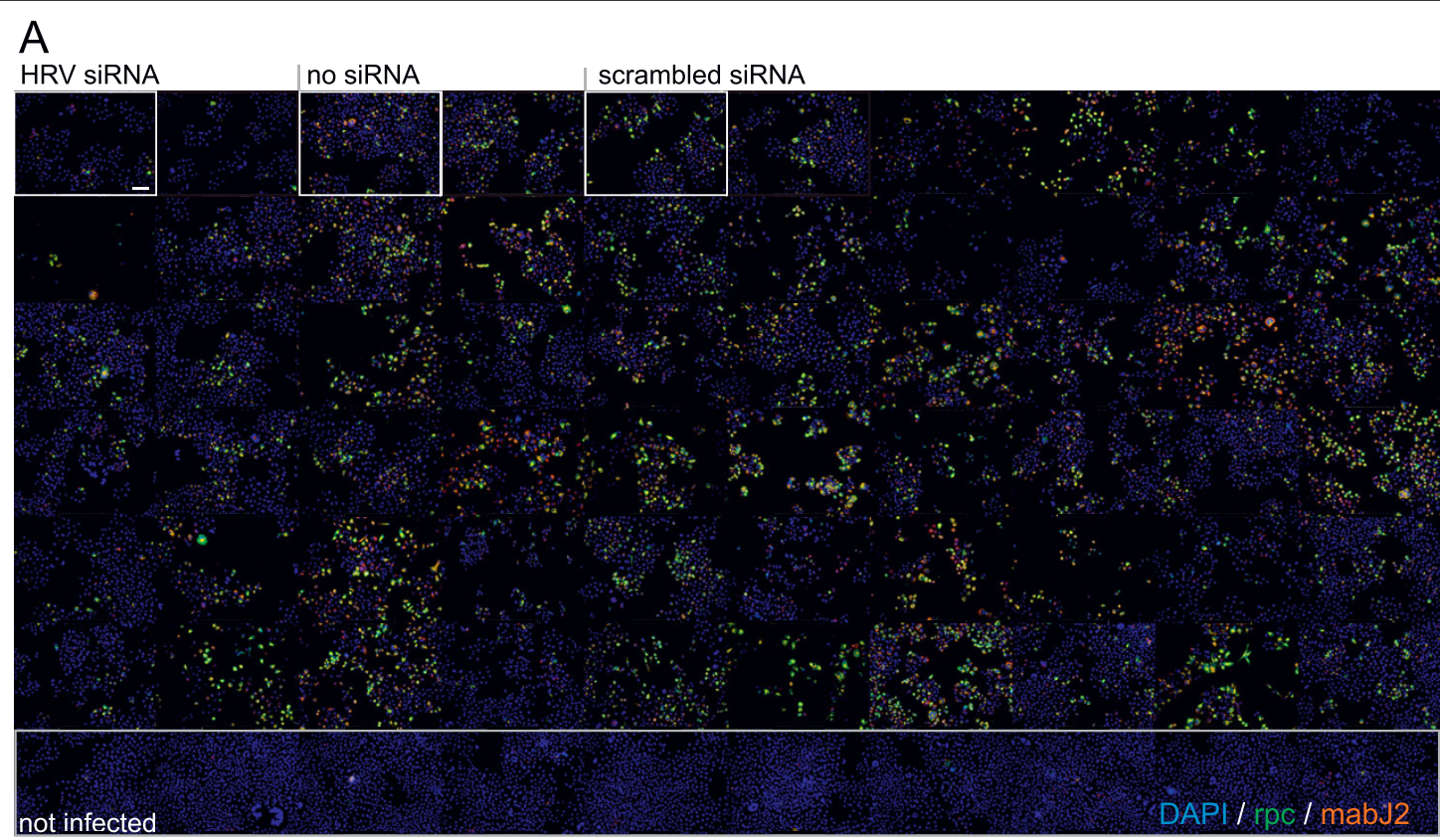

B zoom ins from A (white boxes)

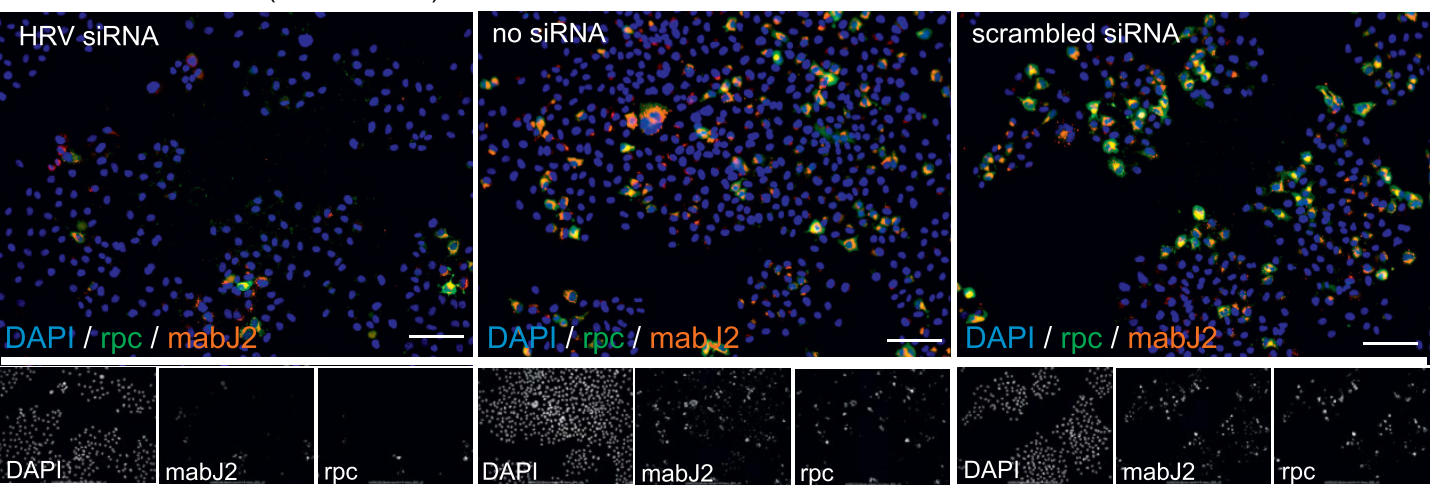

C Correlations of mabJ2 and mabR16-7 infection readouts for siRNA profiling
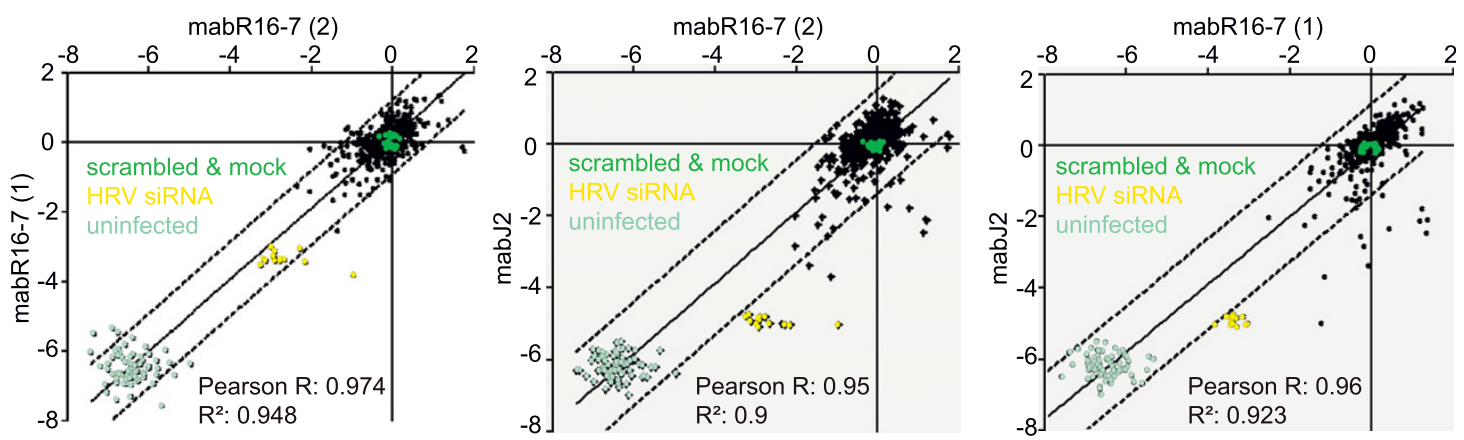

Figure 5 The mabJ2 dsRNA replication assay is compatible with high content image based siRNA infection screens. (A) Overview montage of an example siRNA screening plate. HeLa cells were infected with HRV14 and stained with a rabbit polyclonal antibody (rpc, green) raised against purified viral capsid, mabJ2 recognizing dsRNA (red) and nuclei (DAPI, blue). One out of nine images per well is shown for each siRNA, which are not specified here. (B) Examples close-ups from wells treated with HRV-targeting (HRV siRNA), no siRNA, or scrambled siRNA, followed by staining as described in (A). Merged colors are shown above, single channel micrographs are in black and white. Scale bars $100 \mu \mathrm{m}$. (C) Normalized HRV16 infection index (log2 transformed) determined by automated microscopy/analysis from three independent siRNA screens. Infection was measured either by mabR16-7 recognizing a VP2 epitope or mabJ2 recognizing replicated dsRNA. 

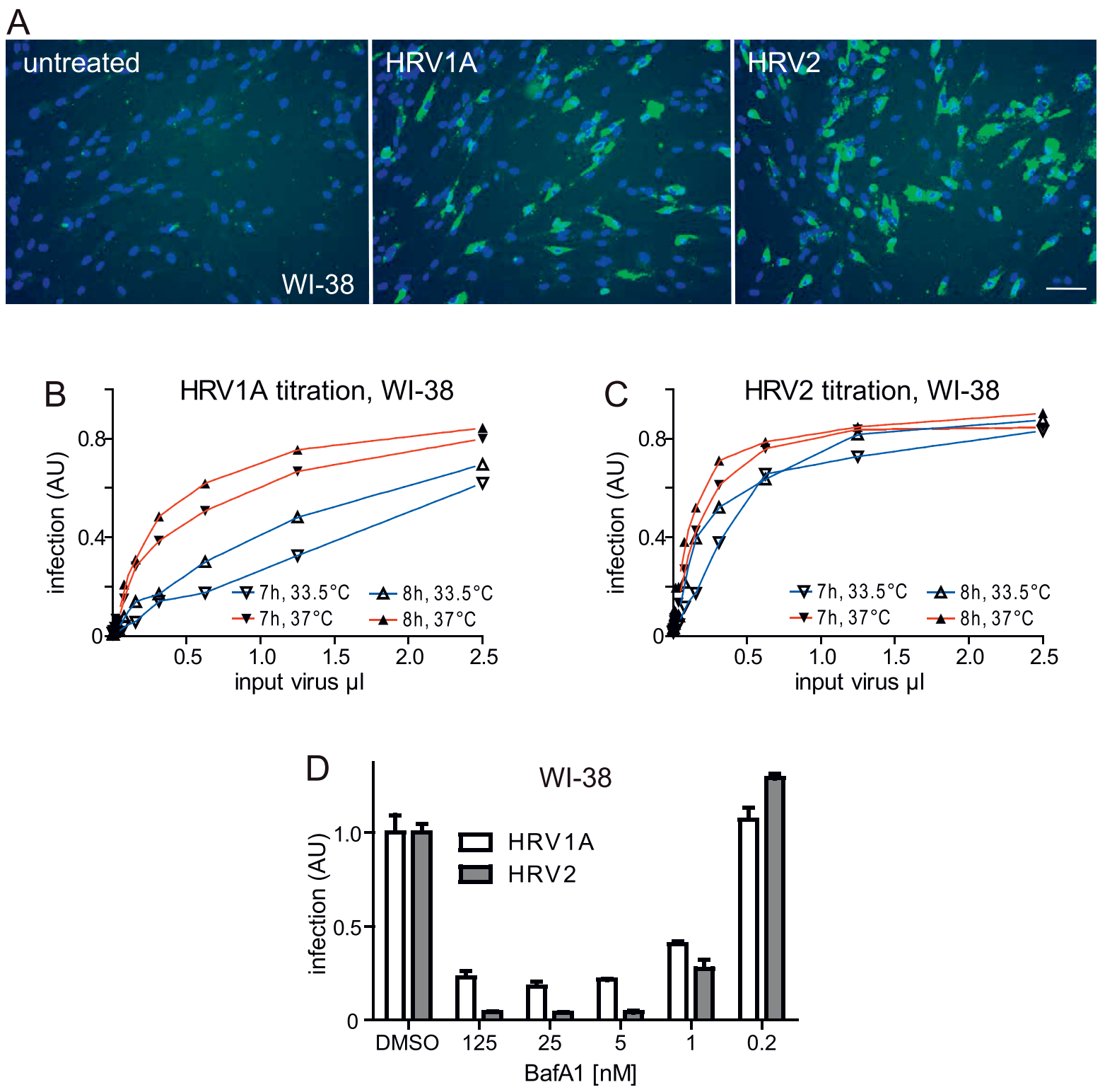

Figure 6 MabJ2 detects HRV1A and 2 infections of diploid human lung airway cells. (A) Example images of WI-38 non-transformed primary human embryonic diploid airway cells inoculated with HRV1A or HRV2 and stained for dsRNA replication centers using mabJ2 (green) and nuclei (DAPI, blue) $7 \mathrm{~h}$ pi. Scale bar $100 \mu \mathrm{m}$. (B, C) Wl-38 cells were inoculated with serial dilutions of HRV1A or HRV2 for 7 or $8 \mathrm{~h}$ at $33.5^{\circ} \mathrm{C}$ (blue) or $37^{\circ} \mathrm{C}$ (red), and infection was quantified by the mabJ2 dsRNA infection assay using automated image acquisition/analysis. The infection index is plotted in arbitrary units (AU), where 1 means all cells infected. (D) Wl-38 cells were pre-treated with increasing concentrations of bafilomycin A1 (BafA1) for 30 min, and infected with HRV1A or HRV2 for $7 \mathrm{~h}$. Quantification by the mabJ2 dsRNA infection assay was by automated image acquisition/analysis and the means $(n=3)$ and SEMs of the normalized infection index relative to DMSO carrier control infected cells are plotted.

screening, and infection readouts are time, dose and temperature-dependent.

Importantly, our assay is compatible with siRNA screening approaches, which have received considerable attention in the last few years, due to the promise to uncover much of the so far hidden host functions that support viral infections. Recently genome wide or subgenomic screens have been published for a variety of viral pathogens, including HIV [57-59], HCV [60,61], dengue virus [62], West Nile virus [63], influenza virus [64-68], human papillomavirus [69] and vaccinia virus [70]. The multiple screens for HIV, influenza virus and $\mathrm{HCV}$, however, identified only very few overlapping genes for the individual viruses. Reasons for such findings have been attributed to the biological nature of cells and viruses, including virus strain differences, cell line differences, cell context-dependent effects and redundancies of host factors. Among the technical reasons for the low 
levels of overlapping hits from the published screens are also the different sources and efficacies of siRNAs, which depended on the manufacturer, or whether single siRNAs or siRNA pools were used. In addition, the different hit scoring algorithms, including post-processing filters and variable accounts for toxicity and specificity, hit ranking algorithms, or consideration of hit assignment to previously known functional networks of cellular pathways can contribute to different hit lists from siRNA screens. Last but not least, the assays for infection are not standardized, that is, different types of infection assays cover variable phases of the viral replication cycle with variable efficacies and, hence, detection sensitivities and hit identifications are poorly informed.

Our data support the notion that mabJ2 detects replicating dsRNA in infected cells rather than genomic RNA from incoming virus particles. MabJ2 is hence useful to measure viral replication. We suggest that mabJ2 (or any similar antibody) can be used to detect infections of any positive-strand RNA virus that is actively replicating. It may even be used to detect dsRNA from certain DNA virus infections [71]. These findings and the fact that mabJ2 detects dsRNA with high sensitivity in solid support based assays [31] open a path towards standardized and reproducible infection assays, and possibly clinical diagnostics.

Our dsRNA replication assay was validated at several levels. The dsRNA readout correlated with single step growth curves, whereby the infectious titers produced per cell were similar to values reported in the literature, that is, in the range of 40 plaque forming units per cell [47]. We have also validated the assay with two proof of concept chemical compounds known to block enterovirus infections, the capsid binding component pleconaril $[23,72]$ and the $2 \mathrm{C}$ protein inhibitor guanidine [50]. While pleconaril was an entry inhibitor with a half maximal inhibition time of about 25 to $30 \mathrm{~min}$, guanidine blocked infection until 2 to $4 \mathrm{~h}$ pi, reflecting the different modes of action of these compounds. Hence, our dsRNA replication assay in the image-based high content format may prove useful also for screening of small chemical libraries against viral infections.

\section{Conclusions}

The mabJ2 RNA replication assay has proven to be a reliable procedure to study enterovirus infections on a systematic level opening new doors for comparative genomic and chemical studies. It fulfils requirements such as robustness, good signal-to-noise ratio and practical usability, making it broadly and systematically applicable for high content infection assays for enteroviruses, and possibly other plus-sense RNA viruses. The assay covers steps required for virus entry, translation and RNA replication, and can be extended to a full replication cycle assay. It is based on a commercially available mouse monoclonal antibody, which is readily accessible for both academic and commercial laboratories. The assay also offers a way to carry out mechanistic studies with many different serotypes, including emerging picornaviruses, and hence identify serotype independent requirements for picornavirus infection.

\section{Methods}

\section{Cell culture and virus production}

HeLa cervical carcinoma cells strain Ohio (from L. Kaiser; Central Laboratory of Virology, University Hospital Geneva, Switzerland) and primary human embryonic lung WI-38 cells [American Type Culture Collection, [73]] were cultured in Dulbecco's Modified Eagle Medium (Sigma-Aldrich) supplemented with L-glutamine (Sigma-Aldrich), non-essential amino acids (SigmaAldrich) and $10 \%$ fetal calf serum (FCS, Sigma-Aldrich) at $37^{\circ} \mathrm{C}$ and $5 \% \mathrm{CO}_{2}$ in a humidified incubator. In all experiments passage numbers were kept at a maximum of 25 post thawing. For infection experiments in 96 well imaging plates (Matrix) 14,000 cells were split in a total of $100 \mu \mathrm{l}$ the day before the experiment. HRV serotypes 1A and16 were provided by W.M. Lee (Department of Pediatrics, School of Medicine and Public Health, University of Wisconsin, Madison, Wisconsin, USA), HRV2, 14 and 37 were from L. Kaiser and CVB3, B4 and A21 were from T. Hyypiä (Department of Virology, University of Turku, Finland).

Both HRVs and CVs were grown in HeLa cells. Briefly, cells were inoculated with a cell lysate stock from the respective serotypes at $33.5^{\circ} \mathrm{C}$ (HRV) or $37^{\circ} \mathrm{C}$ (CV) over night in infection media (IM/FC-DMEM supplemented with L-glutamine, $30 \mathrm{mM} \mathrm{MgCl}_{2}$ and $2 \%$ FCS). When CPE was visible in $80-90 \%$ of the cells, media was removed and cells harvested by scraping and pelleting, lysed by 3 freeze/thaw cycles and centrifuged at $2500 \times \mathrm{g}$ for $10 \mathrm{~min}$. Aliquots of the supernatants containing stock virus were stored at $-80^{\circ} \mathrm{C}$. All serotypes used in this study were analyzed by reverse transcriptase-polymerase chain reaction and diagnostic sequencing of the 5'UTR and/or capsid regions and found to be virtually identical with the published sequences. For details, see additional files 5, 6, 7, 8.

\section{Infections and immunocytochemistry}

Viruses where added to cells in infection media/BSA (DMEM supplemented with L-glutamine, $30 \mathrm{mM} \mathrm{MgCl}$ and $0.2 \%$ BSA, Sigma-Aldrich). For all the compound and siRNA experiments, moi was chosen such that approximately 20 to $40 \%$ of the cells were infected at 7 h pi. Cells were fixed by adding $1 / 3$ volume of $16 \%$ para-formaldehyde directly to the cells in culture media. Fixation was for either $15 \mathrm{~min}$ at room temperature or 
long term storage at $4^{\circ} \mathrm{C}$. Cells were washed with $\mathrm{PBS}$, $\mathrm{PBS} / 25 \mathrm{mM} \mathrm{NH}_{4} \mathrm{Cl}$ and PBS, permeabilized with $0.2 \%$ Triton X-100 (Sigma-Aldrich) and washed twice with PBS and blocked with PBS containing 1\% BSA (Fraction $\mathrm{V}$, Sigma). Antibodies detecting viral protein antigens were used as follows: for HRV1A and HRV16 mabR16-7 [35], for HRV2 mab8F5 [74], for HRV14, 37 and CVB3, B4 the rabbit polyclonal antisera (rpc, W.M. Lee, unpublished). MabJ2 and K1 used to detect dsRNA of infected cells $[31,71]$ were obtained from English \& Scientific Consulting (Bt. Szirák, Hungary). Fixed and permeabilized cells were incubated at room temperature for $1 \mathrm{~h}$ with diluted mabJ2 in PBS/1\%BSA $(0.33 \mu \mathrm{g} / \mathrm{ml}$ which corresponded to a 1:1500 dilution of the $0.5 \mathrm{mg} / \mathrm{ml}$ antibody). Cells were washed twice with PBS and incubated with Alexa-fluor labelled secondary antibodies (Invitrogen) at $0.2 \mu \mathrm{g} / \mathrm{ml}$ for $1 \mathrm{~h}$. Nuclei were stained with DAPI, and cells on coverslips mounted in mounting media (Dako), or the 96 well imaging plates were stored at $4^{\circ} \mathrm{C}$ in $\mathrm{PBS} / \mathrm{NaN}_{3}$.

\section{Automated image acquisition and data analysis}

Automated image acquisition was performed with an ImageXpress Micro (Molecular Devices) equipped with a CoolSNAP HQ 12bit greyscale camera (Roper Scientific) and 10×/NA 0.5 objective (Nikon). Routinely, 9-20 images per 96 well were acquired leading to an average of 5000-12000 cells analyzed per well. For high resolution images, an Olympus IX81 equipped with a $60 \times / 1.4$ NA. objective and oil immersion was used. Image overlays were made using MetaXpress (Molecular Devices) and ImageJ (NIH Image, http://rsbweb.nih.gov/nihimage/). Images were analyzed using a custom written Matlab routine. Briefly, a canny edge algorithm was used to identify areas of all the nuclei stained with DAPI [75] and infected cells stained for newly synthesized viral protein or replicating dsRNA were identified by a user-defined thresholding method scoring staining intensity and size. If the overlap of the nuclear and infection signals exceeded a user defined threshold, a cell was scored as infected. Data analysis was performed using Prism (version 5.01, Graphpad), and data for different serotypes were plotted in the order of HRV1A, 2, $14,16,37$, and CVB3, B4 as infection indices (fraction of infected cells per total cell number, indicated as arbitrary units) unless stated otherwise.

\section{ICAM-1 receptor blocking and compound assays}

HeLa cells were pre-incubated with mouse monoclonal anti-ICAM-1 antibody mab15.2L (Santa Cruz) at $37^{\circ} \mathrm{C}$ at a concentration of $0.5 \mu \mathrm{g}$ of antibody in $50 \mu \mathrm{l}$ of infection medium/BSA per 96 well for $1 \mathrm{~h}$, followed by infection for $7 \mathrm{~h}$ and staining for dsRNA replication centers. For compound assays cells were pre-incubated for 30 min with compounds diluted in infection medium/BSA prior to virus addition. Virus diluted in infection medium/BSA was added to the cells at $37^{\circ} \mathrm{C}$ for $7 \mathrm{~h}$, and cells were fixed and immunostained. All compounds were dissolved in dimethyl sulfoxid (DMSO, cell culture grade, Sigma-Aldrich) and the respective concentrations of DMSO were used as controls. Pleconaril was a kind gift from 3-V Biosciences and guanidine- $\mathrm{HCl}$ was bought from Sigma-Aldrich.

\section{siRNA screens}

For siRNA experiments, siRNA oligos (Qiagen) were spotted in OptiMEM-I (Gibco) at a final concentration of $50 \mathrm{nM}$ in 96 well imaging plates (Matrix). Lipofectamine 2000 (Invitrogen)/OptiMEM-I was added to a total volume of $25 \mu \mathrm{l}$, and $3000 \mathrm{HeLa}$ cells were seeded into each 96 well in a total of $100 \mu$ per well. Transfected cells were incubated for $65 \mathrm{~h}$, followed by infection at $37^{\circ} \mathrm{C}$ for $7 \mathrm{~h}$ and fixation/staining as indicated above. Specific siRNA oligos directed against the structural protein VP4 (termed HRV siRNA) were designed according to the specific genomic sequence of the particular serotype [76].

\section{Additional material}

Additional file 1: Fig. S1. Automated image analysis details. The matlab scoring algorithm (1) detects edges of the nuclei (A, DAPI) and infection ( $B$, immunostaining) channels using a canny edge algorithm and user defined thresholds and forms areas by closing the edges. (2) Areas below or above a set size-threshold are excluded from both channels (A2, B2) leading to the final total cell (A3) and infection (B3) mask. Merging of both masks leads to the final result indicating infected and not infected cells (as shown in Fig. 1C). Scale bar corresponds to $100 \mu \mathrm{m}$.

Additional file 2: Fig. S2. Dose and temperature dependent formation of dsRNA replication centers of HRV1A, 2, 14, 37 or CVB4 infected HeLa cells. The dose dependencies of HRV1A, 2, 14, 37 and CVB4 infections at $33.5^{\circ}$ (blue) or $37^{\circ} \mathrm{C}$ (red) were determined for the mabJ2 dsRNA infection assay in HeLa cells by two fold serial dilutions of inocula. Infection was scored using automated image acquisition/analysis. Means and SEMs of one representative triplicate are shown.

Additional file 3: Fig. S3. Time and temperature dependent formation of dsRNA replication centers of HRV1A, 2, 14, 37 and CVB4 and A21 infected HeLa cells. The time dependencies of of HRV1A, 2, 14, 37 and CVB4 and $\mathrm{A} 21$ infections at $33.5^{\circ} \mathrm{C}$ (blue) or $37^{\circ} \mathrm{C}$ (red) were determined for the mabJ2 dsRNA infection assay in HeLa cells by infection for 300 to 700 min. Infections were scored using automated image analysis. Means and SEMs of one representative triplicate are shown.

Additional file 4: Fig. S4. MabJ2 dsRNA replication center assay in normal human lung airway cells. (A) Example images of Wl-38 nontransformed primary human embryonic diploid airway cells inoculated with the indicated HRV and CV serotypes and stained for dsRNA replication centers using mabJ2 (green) and nuclei (DAPI, blue) $7 \mathrm{~h}$ pi. Scale bar $100 \mu \mathrm{m}$. (B) Wl-38 cells were inoculated with serial dilutions of the indicated HRV and CV serotypes for 7 or $8 \mathrm{~h}$ at $33.5^{\circ} \mathrm{C}$ (blue) or $37^{\circ} \mathrm{C}$ (red), and infection was quantified by the mabJ2 dsRNA infection assay using automated image acquisition/analysis. The infection index is plotted in arbitrary units (AU), where 1 means all cells infected.

Additional file 5: Table S1. List of primers for diagnostic sequencing of HRV and CV serotypes. 
Additional file 6: Table S2. Top results of Blastn alignments of HRV and CV diagnostic PCR products.

Additional file 7: Table S3. DNA sequences of reverse transcribed PCR products from five HRV and two CV serotypes.

Additional file 8: Supplemental references

\section{Acknowledgements}

We are grateful to M. Kikkert (Molecular Virology Laboratory, Department of Medical Microbiology, Leiden, The Netherlands) for providing mabJ2 for initial experiments, Dr. T. Hyypiä for coxsackievirus strains and advice, Dr.'s C. Tapparel and L. Kaiser for advice in diagnostic sequencing and providing HRV2, 14, 37 and HeLa-Ohio cells, and Qian Feng (Department of Medical Microbiology, Radboud University Nijmegen) for comments on the manuscript.

\section{Author details}

${ }^{1}$ Institute of Molecular Life Sciences, University of Zurich, Winterthurerstrasse 190, CH-8057 Zurich, Switzerland. 'Molecular Life Sciences Graduate School, ETH and University of Zurich, Switzerland. ${ }^{3} 3-V$ Biosciences $\mathrm{GmbH}$, Schlieren, Switzerland \& Menlo Park, CA, USA. ${ }^{4}$ Department of Pediatrics, School of Medicine and Public Health, University of Wisconsin, Madison, Wisconsin, USA.

\section{Authors' contributions}

AJ set up and optimized the assay and performed all experiments documented by figures; UFG had the initial idea to test mabJ2 in high content infection screening; SM provided the Matlab code for analysis of infection experiments; $A D, P R, A J$ and $M L$ designed and performed the diagnostic sequencing of HRVs and CVs; WML provided essential antibodies and protocols for virus growth, UFG \& AJ wrote the manuscript.All authors have read and approved the final manuscript.

\section{Competing interests}

The project was in part financially supported by a grant from 3-V Biosciences Inc (Zurich, Switzerland, and Menlo Park, CA, USA), the Swiss National Science Foundation, the Swiss SystemsX.ch initiative, grant InfectX and the Kanton Zurich to UFG. The funders had no role in study design, data collection and analysis or preparation of the manuscript. UFG is a founder of 3-V Biosciences, and UFG and SM are shareholders of 3-V Biosciences.

Received: 19 August 2010 Accepted: 11 October 2010 Published: 11 October 2010

\section{References}

1. Whitton $J \mathrm{~L}$, Cornell $\mathrm{CT}$, Feuer R: Host and virus determinants of picornavirus pathogenesis and tropism. Nat Rev Microbiol 2005, 3:765-776.

2. Mackay IM: Human rhinoviruses: the cold wars resume. J Clin Virol 2008, 42:297-320.

3. Gern JE: The ABCs of rhinoviruses, wheezing, and asthma. J Virol 2010, 84:7418-7426.

4. Traves SL, Proud D: Viral-associated exacerbations of asthma and COPD. Curr Opin Pharmacol 2007, 7:252-258.

5. Palmenberg AC, Spiro D, Kuzmickas R, Wang S, Djikeng A, Rathe JA, FraserLiggett CM, Liggett SB: Sequencing and analyses of all known human rhinovirus genomes reveal structure and evolution. Science 2009, 324:55-59.

6. Thompson D, Muriel P, Russell D, Osborne P, Bromley A, Rowland M, Creigh-Tyte S, Brown C: Economic costs of the foot-and-mouth disease outbreak in the United Kingdom in 2001. Rev Sci Tech 2002, 21:675-687.

7. Rossmann MG, Johnson JE: Icosahedral RNA virus structure. Annu Rev Biochem 1989, 58:533-573.

8. Racaniello V: Picornaviridae: the viruses and their replication. In Fields Virology. Edited by: Knipe D, Howley P. Philadelphia, PA, USA: Wolters Kluwer, Lippincott Williams , 5 2007:1:795-838.

9. Dales S, Eggers HJ, Tamm I, Palade GE: Electron Microscopic Study of the Formation of Poliovirus. Virology 1965, 26:379-389.
10. Grimley PM, Berezesky IK, Friedman RM: Cytoplasmic structures associated with an arbovirus infection: loci of viral ribonucleic acid synthesis. J Virol 1968, 2:1326-1338.

11. Friedman RM, Levin JG, Grimley PM, Berezesky IK: Membrane-associated replication complex in arbovirus infection. J Virol 1972, 10:504-515.

12. Froshauer S, Kartenbeck J, Helenius A: Alphavirus RNA replication occurs on the cytoplasmic surface of endosomes and lysosomes. J Cell Biol 1988, 107:2075-2086.

13. Lee JY, Marshall JA, Bowden DS: Characterization of rubella virus replication complexes using antibodies to double-stranded RNA. Virology 1994, 200:307-312.

14. Magliano D, Marshall JA, Bowden DS, Vardaxis N, Meanger J, Lee JY: Rubella virus replication complexes are virus-modified lysosomes. Virology 1998, 240:57-63.

15. Bienz K, Egger D, Rasser Y, Bossart W: Intracellular distribution of poliovirus proteins and the induction of virus-specific cytoplasmic structures. Virology 1983, 131:39-48.

16. Mackenzie J: Wrapping things up about virus RNA replication. Traffic 2005, 6:967-977.

17. Gosert R, Egger D, Lohmann V, Bartenschlager R, Blum HE, Bienz K, Moradpour D: Identification of the hepatitis $C$ virus RNA replication complex in Huh-7 cells harboring subgenomic replicons. J Virol 2003, 77:5487-5492

18. Welsch S, Miller S, Romero-Brey I, Merz A, Bleck CK, Walther P, Fuller SD, Antony C, Krijnse-Locker J, Bartenschlager R: Composition and threedimensional architecture of the dengue virus replication and assembly sites. Cell Host Microbe 2009, 5:365-375.

19. King $L$, Moore $N$ : Evidence for the presence of a genome linked protein in two insect picornaviruses, cricket paralysis virus and Drosophila C virus. FEMS Lett 1988, 50:41.

20. Cherry S, Kunte A, Wang H, Coyne C, Rawson RB, Perrimon N: COPI activity coupled with fatty acid biosynthesis is required for viral replication. PLOS Pathog 2006, 2:e102.

21. Sturmer M, Doerr HW, Gurtler L: Human immunodeficiency virus: 25 years of diagnostic and therapeutic strategies and their impact on hepatitis $B$ and C virus. Med Microbiol Immunol 2009, 198:147-155.

22. Patick AK: Rhinovirus chemotherapy. Antiviral Res 2006, 71:391-396.

23. Pevear DC, Tull TM, Seipel ME, Groarke JM: Activity of pleconaril against enteroviruses. Antimicrob Agents Chemother 1999, 43:2109-2115.

24. Van den Broeke C, Radu M, Chernoff J, Favoreel HW: An emerging role for p21-activated kinases (Paks) in viral infections. Trends Cell Biol 2010, 20:160-169.

25. Kalin S, Amstutz B, Gastaldelli M, Wolfrum N, Boucke K, Havenga M, DiGennaro F, Liska N, Hemmi S, Greber UF: Macropinocytotic uptake and infection of human epithelial cells with species B2 adenovirus type 35. J Virol 2010, 84:5336-5350.

26. Mercer J, Helenius A: Vaccinia virus uses macropinocytosis and apoptotic mimicry to enter host cells. Science 2008, 320:531-535.

27. Liberali P, Kakkonen E, Turacchio G, Valente C, Spaar A, Perinetti G, Bockmann RA, Corda D, Colanzi A, Marjomaki V, Luini A: The closure of Pak1-dependent macropinosomes requires the phosphorylation of CtBP1/BARS. Embo J 2008, 27:970-981.

28. Amstutz B, Gastaldelli M, Kälin S, Imelli N, Boucke K, Wandeler E, Mercer J, Hemmi S, Greber UF: Subversion of CtBP1 controlled macropinocytosis by human Adenovirus serotype 3. EMBO J 2008, 27:956-966.

29. Coyne CB, Bergelson JM: Virus-Induced Abl and Fyn Kinase Signals Permit Coxsackievirus Entry through Epithelial Tight Junctions. Cell 2006, 124:119-131.

30. Backert S, Feller SM, Wessler S: Emerging roles of Abl family tyrosine kinases in microbial pathogenesis. Trends Biochem Sci 2008, 33:80-90.

31. Schonborn J, Oberstrass J, Breyel E, Tittgen J, Schumacher J, Lukacs N: Monoclonal antibodies to double-stranded RNA as probes of RNA structure in crude nucleic acid extracts. Nucleic Acids Res 1991, 19:2993-3000.

32. Targett-Adams P, Boulant S, McLauchlan J: Visualization of doublestranded RNA in cells supporting hepatitis C virus RNA replication. J Virol 2008, 82:2182-2195.

33. Bowden DS, Pedersen JS, Toh BH, Westaway EG: Distribution by immunofluorescence of viral products and actin-containing cytoskeletal filaments in rubella virus-infected cells. Arch Virol 1987, 92:211-219. 
34. Couch R: Rhinoviruses. In Laboratory diagnosis of viral infections. Edited by: Lennette EH. New York, NY: Marcel Dekker, Inc; 1992.

35. Mosser AG, Brockman-Schneider R, Amineva S, Burchell L, Sedgwick JB, Busse WW, Gern JE: Similar frequency of rhinovirus-infectible cells in upper and lower airway epithelium. J Infect Dis 2002, 185:734-743.

36. Lanke $\mathrm{KH}$, van der Schaar HM, Belov GA, Feng Q, Duijsings $D$, Jackson $C L$, Ehrenfeld E, van Kuppeveld FJ: GBF1, a guanine nucleotide exchange factor for Arf, is crucial for coxsackievirus B3 RNA replication. J Virol 2009, 83:11940-11949.

37. Novak JE, Kirkegaard K: Improved method for detecting poliovirus negative strands used to demonstrate specificity of positive-strand encapsidation and the ratio of positive to negative strands in infected cells. J Virol 1991, 65:3384-3387.

38. Greve JM, Davis G, Meyer AM, Forte CP, Yost SC, Marlor CW, Kamarck ME, McClelland A: The major human rhinovirus receptor is ICAM-1. Cell 1989, 56:839-834.

39. Jedrzejas MJ, Miglietta J, Griffin JA, Luo M: Structure of a monoclonal antiICAM-1 antibody R6.5 Fab fragment at 2.8 A resolution. Acta Crystallogr D Biol Crystallogr 1995, 51:380-385.

40. Bella J, Rossmann MG: ICAM-1 receptors and cold viruses. Pharm Acta Helv 2000, 74:291-297.

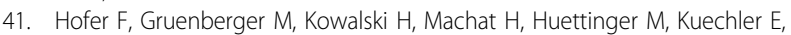
Blass D: Members of the low density lipoprotein receptor family mediate cell entry of a minor-group common cold virus. Proc Natl Acad Sci USA 1994, 91:1839-1842.

42. Shafren DR, Williams DT, Barry RD: A decay-accelerating factor-binding strain of coxsackievirus $B 3$ requires the coxsackievirus-adenovirus receptor protein to mediate lytic infection of rhabdomyosarcoma cells. Journal of Virology 1997, 71:9844-9848

43. Papadopoulos NG, Sanderson G, Hunter J, Johnston SL: Rhinoviruses replicate effectively at lower airway temperatures. Journal of Medical Virology 1999, 58:100-104

44. Schroth MK, Grimm E, Frindt P, Galagan DM, Konno SI, Love R, Gern JE: Rhinovirus replication causes RANTES production in primary bronchial epithelial cells. Am J Respir Cell Mol Biol 1999, 20:1220-1228.

45. Gern JE, Galagan DM, Jarjour NN, Dick EC, Busse WW: Detection of rhinovirus RNA in lower airway cells during experimentally induced infection. Am J Respir Crit Care Med 1997, 155:1159-1161.

46. Hayden FG: Rhinovirus and the lower respiratory tract. Rev Med Virol 2004 14:17-31.

47. Fiala M: Plaque formation by 55 rhinovirus serotypes. Appl Microbiol 1968 16:1445-1450.

48. Schmidtke M, Hammerschmidt E, Schuler S, Zell R, Birch-Hirschfeld E, Makarov VA, Riabova OB, Wutzler P: Susceptibility of coxsackievirus B3 laboratory strains and clinical isolates to the capsid function inhibito pleconaril: antiviral studies with virus chimeras demonstrate the crucial role of amino acid 1092 in treatment. J Antimicrob Chemother 2005, 56:648-656.

49. Shepard DA, Heinz BA, Rueckert RR: WIN 52035-2 inhibits both attachment and eclipse of human rhinovirus 14. Journal of Virology 1993, 67:2245-2245.

50. Rightsel WA, Dice JR, Mc AR, Timm EA, Mc LI Jr, Dixon GJ, Schabel FM Jr: Antiviral effect of guanidine. Science 1961, 134:558-559.

51. Loddo B, Ferrari W, Brotzu G, Spanedda A: In vitro inhibition of infectivity of polio viruses by guanidine. Nature 1962, 193:97-98.

52. Pincus SE, Diamond DC, Emini EA, Wimmer E: Guanidine-selected mutants of poliovirus: mapping of point mutations to polypeptide $2 \mathrm{C}$. J Virol 1986, 57:638-646.

53. Pincus SE, Wimmer E: Production of guanidine-resistant and -dependent poliovirus mutants from cloned cDNA: mutations in polypeptide $2 \mathrm{C}$ are directly responsible for altered guanidine sensitivity. J Virol 1986, 60:793-796.

54. Bowman EJ, Siebers A, Altendorf K: Bafilomycins: a class of inhibitors of membrane ATPases from microorganisms, animal cells, and plant cells. Proc Natl Acad Sci USA 1988, 85:7972-7976.

55. Brabec M, Baravalle G, Blaas D, Fuchs R: Conformational changes, plasma membrane penetration, and infection by human rhinovirus type 2: role of receptors and low pH. J Virol 2003, 77:5370-5377.

56. Gern JE, Mosser AG, Swenson CA, Rennie PJ, England RJ, Shaffer J, Mizoguchi $\mathrm{H}$ : Inhibition of rhinovirus replication in vitro and in vivo by acid-buffered saline. J Infect Dis 2007, 195:1137-1143.
57. Brass AL, Dykxhoorn DM, Benita Y, Yan N, Engelman A, Xavier RJ, Lieberman J, Elledge SJ: Identification of host proteins required for HIV infection through a functional genomic screen. Science 2008, 319:921-926.

58. Zhou H, Xu M, Huang Q, Gates AT, Zhang XD, Castle JC, Stec E, Ferrer M, Strulovici B, Hazuda DJ, Espeseth AS: Genome-scale RNAi screen for host factors required for HIV replication. Cell Host Microbe 2008, 4:495-504.

59. Konig R, Zhou Y, Elleder D, Diamond TL, Bonamy GM, Irelan JT, Chiang CY, Tu BP, De Jesus PD, Lilley CE, et al: Global analysis of host-pathogen interactions that regulate early-stage HIV-1 replication. Cell 2008, 135:49-60.

60. Li Q, Brass AL, Ng A, Hu Z, Xavier RJ, Liang TJ, Elledge SJ: A genome-wide genetic screen for host factors required for hepatitis $C$ virus propagation. Proc Natl Acad Sci USA 2009, 106:16410-16415.

61. Coller KE, Berger KL, Heaton NS, Cooper JD, Yoon R, Randall G: RNA interference and single particle tracking analysis of hepatitis $C$ virus endocytosis. PLoS Pathog 2009, 5:e1000702.

62. Sessions OM, Barrows NJ, Souza-Neto JA, Robinson TJ, Hershey CL, Rodgers MA, Ramirez JL, Dimopoulos G, Yang PL, Pearson JL, GarciaBlanco MA: Discovery of insect and human dengue virus host factors. Nature 2009, 458:1047-1050.

63. Krishnan MN, Ng A, Sukumaran B, Gilfoy FD, Uchil PD, Sultana H, Brass AL, Adametz R, Tsui M, Qian F, et al: RNA interference screen for human genes associated with West Nile virus infection. Nature 2008, 455:242-245.

64. Hao L, Sakurai A, Watanabe T, Sorensen E, Nidom CA, Newton MA, Ahlquist $\mathrm{P}$, Kawaoka Y: Drosophila RNAi screen identifies host genes important for influenza virus replication. Nature 2008, 454:890-893.

65. Karlas A, Machuy N, Shin Y, Pleissner KP, Artarini A, Heuer D, Becker D, Khalil H, Ogilvie LA, Hess $S$, et al: Genome-wide RNAi screen identifies human host factors crucial for influenza virus replication. Nature 2010, 463:818-822.

66. Konig $\mathrm{R}$, Stertz $\mathrm{S}$, Zhou $\mathrm{Y}$, Inoue A, Hoffmann HH, Bhattacharyya S, Alamares JG, Tscherne DM, Ortigoza MB, Liang $Y$, et al: Human host factors required for influenza virus replication. Nature 2010, 463:813-817.

67. Shapira SD, Gat-Viks I, Shum BO, Dricot A, de Grace MM, Wu L, Gupta PB, Hao T, Silver SJ, Root DE, et al: A physical and regulatory map of hostinfluenza interactions reveals pathways in H1N1 infection. Cell 2009, 139:1255-1267.

68. Brass AL, Huang IC, Benita Y, John SP, Krishnan MN, Feeley EM, Ryan BJ, Weyer JL, van der Weyden L, Fikrig E, et al: The IFITM proteins mediate cellular resistance to influenza A H1N1 virus, West Nile virus, and dengue virus. Cell 2009, 139:1243-1254.

69. Smith JA, White EA, Sowa ME, Powell ML, Ottinger M, Harper JW, Howley PM: Genome-wide siRNA screen identifies SMCX, EP400, and Brd4 as E2-dependent regulators of human papillomavirus oncogene expression. Proc Natl Acad Sci USA 2010, 107:3752-3757.

70. Moser TS, Jones RG, Thompson CB, Coyne CB, Cherry S: A Kinome RNAi Screen Identified AMPK as Promoting Poxvirus Entry through the Control of Actin Dynamics. PLoS Pathog 2010, 6:e1000954.

71. Weber F, Wagner V, Rasmussen SB, Hartmann R, Paludan SR: Doublestranded RNA is produced by positive-strand RNA viruses and DNA viruses but not in detectable amounts by negative-strand RNA viruses. $J$ Virol 2006, 80:5059-5064.

72. Florea NR, Maglio D, Nicolau DP: Pleconaril, a novel antipicornaviral agent. Pharmacotherapy 2003, 23:339-348.

73. Hayflick L, Moorhead PS: The serial cultivation of human diploid cell strains. Exp Cell Res 1961, 25:585-621.

74. Skern T, Neubauer C, Frasel L, Grundler P, Sommergruber W, Zorn M, Kuechler E, Blaas D: A neutralizing epitope on human rhinovirus type 2 includes amino acid residues between 153 and 164 of virus capsid protein VP2. J Gen Virol 1987, 68(Pt 2):315-323.

75. Canny J: A Computational Approach to Edge-Detection. leee Transactions on Pattern Analysis and Machine Intelligence 1986, 8:679-698.

76. Phipps KM, Martinez A, Lu J, Heinz BA, Zhao G: Small interfering RNA molecules as potential anti-human rhinovirus agents: in vitro potency, specificity, and mechanism. Antiviral Res 2004, 61:49-55.

doi:10.1186/1743-422X-7-264

Cite this article as: Jurgeit et al: An RNA replication-center assay for high content image-based quantifications of human rhinovirus and coxsackievirus infections. Virology Journal 2010 7:264 